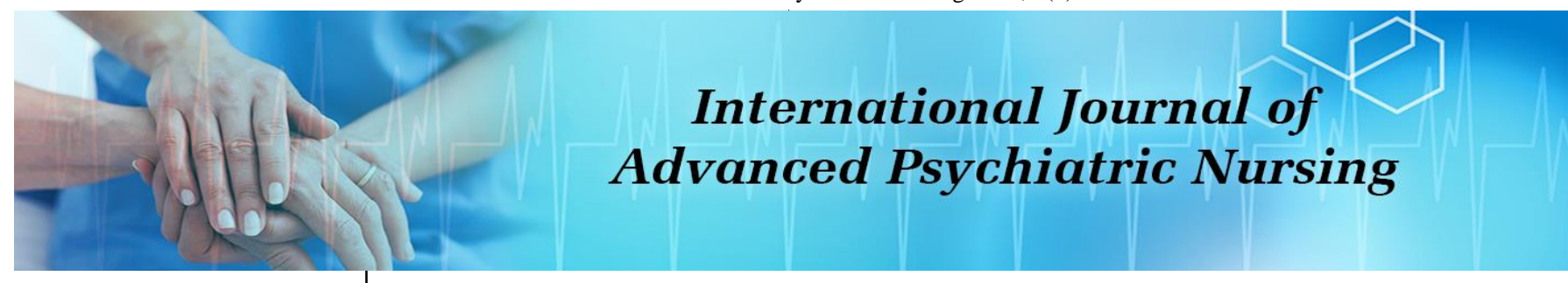

E-ISSN: 2664-1356 P-ISSN: 2664-1348 www.psychiatricjournal.net IJAPN 2020; 2(2): 56-57

Received: 16-05-2020

Accepted: 18-06-2020

\section{S Seethalakshmi}

Assistant Professor,

KMCH College of Nursing,

Coimbatore, Tamil Nadu,

India

\section{Pradhiba}

Assistant Professor,

KMCH College of Nursing,

Coimbatore, Tamil Nadu,

India
Corresponding Author:

S Seethalakshmi

Assistant Professor,

KMCH College of Nursing,

Coimbatore, Tamil Nadu,

India

\section{Building resilience in child}

\section{S Seethalakshmi and Pradhiba}

DOI: https://doi.org/10.33545/26641348.2020.v2.i2b.43

\section{Abstract}

All children are capable of working through challenges and coping with stress. Resilience is the ability to bounce back from stress, adversity, failure, challenges, or even trauma. It's not something that kids either have or don't have; it's a skill that kids develop as they grow. Resilient kids are more likely to take healthy risks because they don't fear falling short of expectations. They are curious, brave, and trusting of their instincts. They know their limits and they push themselves to step outside of their comfort zones. This helps them reach for their long-term goals and it helps them solve problems independently.

Keywords: resilience children, instincts, stressed children

\section{Introduction}

Resilience is an important trait for all of us, and an essential one for our children to develop. Resilience creates happier, less stressed children wherever they are-whether it's at home, school, before and after school care or attending school holiday programs. Having a whole lot of resilience can only be a good thing!

\section{What is resilience?}

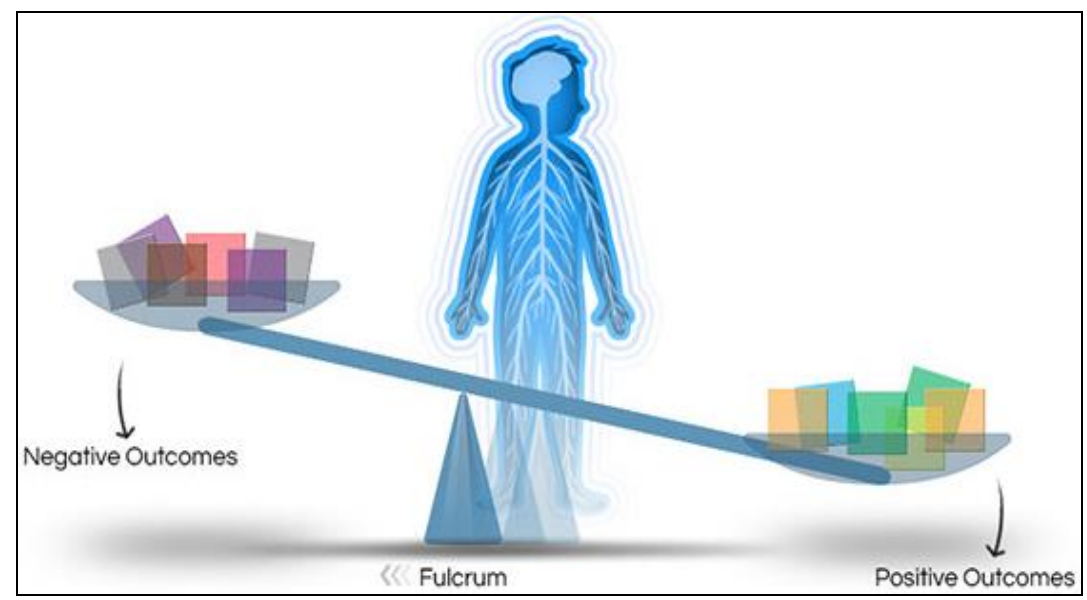

One way to understand the development of resilience is to visualize a balance scale or seesaw. Protective experiences and coping skills on one side counterbalance significant adversity on the other. Resilience is evident when a child's health and development tips toward positive outcomes-even when a heavy load of factors is stacked on the negative outcome side.

When we talk about resilience it is a person's ability to cope with the ups and downs of life. For children it also encompasses how they deal with the challenges they might face throughout their childhood. This could mean dealing with events like a death in the family, moving to a new school or starting out at a new school holiday program.

\section{Building resilience in children}

Building resilience in children helps them to overcome obstacles more easily and reduces the chances of them suffering from anxiety or other stress-related disorders. 
It is during our childhood that we're most actively influenced by the people around us and the situations that encounter. As children, we begin to develop our identity and place in the world, but in turn we are vulnerable to difficulties that we may not know how to handle, and that may leave a significant impact on us. This is why building resilience in youth is crucial. Children may have to deal with all sorts of difficult situations, such as moving house, parents divorcing, difficult exams, losing friends, bullying, and loss and grief.

Without resilience, these can cause considerable stress and even have long-lasting effects, which can take time and dedication to overcome in adolescence and adulthood. It therefore makes sense to integrate resilience in education. Helping them learn this fundamental skill during a time when they are open to adopting new ways of thinking is an effective and beneficial approach.

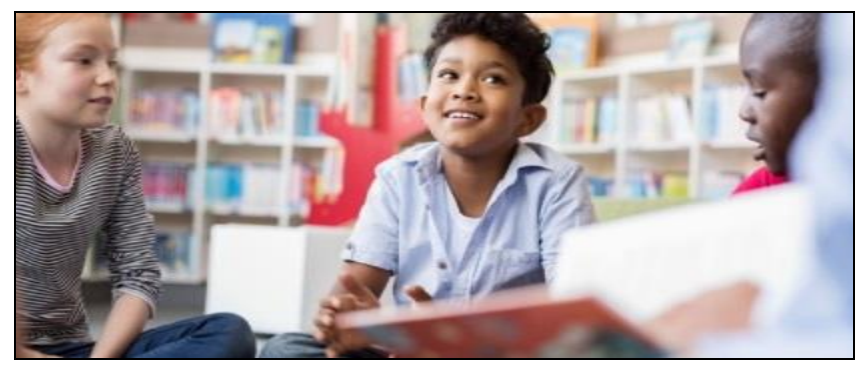

Characteristics of a resilient child

A child who responds well to difficulties in life will often have the following characteristics

- A strong sense of independence, autonomy, and selfconfidence.

- Ability to communicate well with others and express themselves.

- Good problem-solving skills.

- Strong empathy and respect for others.

- Active interest in school activities.

- Responds well to instructions and guidance.

- Knows how to ask for support.

- Open to trying new things.

While no two children are alike, these are good indicators that a child is resilient. Oppositely, children who have room to work on their resilience may avoid problem-solving and may not feel confident in themselves or in communicating. They may also resist guidance and support and avoid new experiences.

Knowing these characteristics can give you a good indicator of who may need extra support in your class, as well as how your interventions will benefit them.

\section{Ideas for building resilience in children}

1. Encourage healthy risk taking.

2. Show acceptance of mistakes and losses.

3. Ask questions to encourage independent thinking.

4. Praise accomplishments in the right way.

5. Define and discuss emotions.

6. Promote optimism and positive thinking.

7. Encourage interaction with others.

8. Show that it's okay to ask for help.

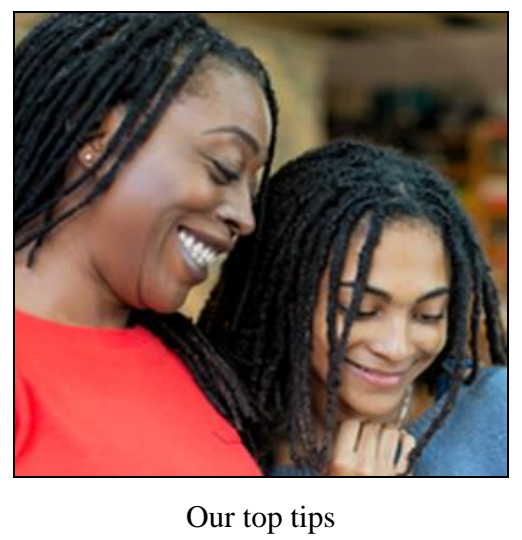

- Help them build positive relationships with their friends and other adults.

- Help them learn to be independent in their actions and thoughts.

- Encourage them to understand, express and manage their emotions.

- Help them build their confidence by taking on challenges and allow them to learn from it even if they do not manage to complete the challenges.

\section{References}

1. Aduen P, Rich BA, Sanchez L, O’Brien K, Alvord MK. (in press). Resilience Builder Program therapy addresses core social deficits in youth with high functioning autism spectrum disorder. Journal of Psychological Abnormalities in Children.

2. Alvord MK, Grados JJ. Enhancing resilience in children: A proactive approach. Professional Psychology: Research and Practice 2005;36:238-245.

3. Alvord MK, Zucker B, Grados JJ. Resilience Builder Program for children and adolescents: Enhancing social competence and self-regulation, a cognitive behavioural group approach. Champaign.

4. Choudhury MA, Pimentel SS, Kendall PC. Childhood anxiety disorders: Parent-child (dis)agreement using a structured interview for the DSM-IV. Journal of the American Academy of Child and Adolescent Psychiatry 2003;42:957-964.

5. Luthar SS, Cicchetti D, Becker B. The construct of resilience: A critical evaluation and guidelines for future work. Child Development 2000;71(3):543-562.

6. Beck JS. Cognitive therapy: basics and beyond. New York: Guilford 1995. 